\title{
EpLearning: ferramenta de ensino-aprendizagem a distância para auxiliar a tarefa da análise da reatividade epitópica no processo de transplante de órgãos
}

\author{
Joana Darc Carvalho de Sousa ${ }^{1}$ \\ Keylla Maria de Sá Urtiga Aita ${ }^{2}$ \\ Airon Wellington Lima dos Santos ${ }^{3}$ \\ Semiramis Jamil Hadad do Monte ${ }^{4}$ \\ Adalberto Socorro da Silva ${ }^{4}$ \\ Luiz Cláudio Demes da Mata Sousa ${ }^{1}$
}

\begin{abstract}
Resumo: Este artigo transcorre sobre os métodos de criação e aplicabilidade de uma ferramenta de aprendizagem eletrônica (e-learning), desenvolvida para viabilizar a disseminação do conhecimento sobre a tarefa da Análise de Reatividade Epitópica no processo de transplantes de órgãos e tecidos, bem como capacitar recursos humanos para desempenhar esta tarefa. A ferramenta em questão foi denominada EpLearning e é resultante de um projeto acadêmico desenvolvido no Programa Institucional de Bolsa de Iniciação Tecnológica e Inovação da Universidade Federal do Piauí (PIBITI-UFPI).
\end{abstract}

Palavras-chave: Análise Epitópica. E-learning. Sistemas Baseados em Conhecimento.

\begin{abstract}
This article takes place on the methods of creation and applicability of an electronic learning tool (e-learning), designed to facilitate the dissemination of knowledge about the Job Analysis of Reactivity epitope in the process of organs and tissues transplantation, as well as empowering human resources to perform this task. The tool is named EpLearning and it is the outcome of an academic project developed in Institutional Technological Initiation Scholarship Program and Innovation of the Federal University of Piaui (PIBITI -UFPI).
\end{abstract}

Keywords: Epitope Analysis. E-learning. Based Systems Knowledge.

\section{Introdução}

Tecnologias da Informação e Comunicação (TICs) exercem um papel cada vez mais importante na forma de nos comunicarmos, aprendermos e vivermos [1]. Com a ascensão das TICs o processo de ensinoaprendizagem tem se adaptado ao surgimento de novas modalidades para a disseminação do conhecimento, como a e-learning, que se trata de uma modalidade de ensino mediada por computador. Com o auxílio dessa tecnologia é possível atender aos interesses de aprendizes com os mais diversos propósitos [2].

A utilização de TICs no processo de ensino-aprendizagem virtual por meio de ferramentas de e-learning dispensa estrutura física para encontros entre professores e aprendizes, gastos com materiais impressos e com os recursos humanos necessários para disseminação da informação. Em contrapartida, disponibiliza aos aprendizes

\footnotetext{
${ }^{1}$ Departamento de Computação, UFPI, Campus Ministro Petrônio Portella - Ininga - Teresina (PI) - Brasil

\{joana.darc.ufpi@gmail.com; claudio.demes@gmail.com\}

${ }^{2}$ Centro de Educação Aberta e a Distância, CEAD/UFPI, Centro, Teresina (PI) - Brasil

\{keyllaurtiga@ufpi.edu.br\}

${ }^{3}$ Centro de Ensino Unificado de Teresina; Estácio CEUT - São João - Teresina (PI) - Brasil

\{aironwellington@gmail.com\}

${ }^{4}$ Laboratório de Imunologia e Biologia Molecular, LIB-UFPI, Campus Ministro Petrônio Portella - Ininga - Teresina (PI) - Brasil

\{libufpi@gmail.com; adalbertosocorro@gmail.com\}
}

http://dx.doi.org/10.5335/rbca.v9i2.6316

Revista Brasileira de Computação Aplicada (ISSN 2176-6649), Passo Fundo, v. 9, n. 2, p. 59-69, jul. 201759 
um ambiente virtual, onde o processo de ensino-aprendizagem acontece através da interação do aprendiz com o computador ou dispositivo móvel, sem restrições de horários para estudos e sem limitações geográficas.

As Tecnologias Educativas em Saúde (TES) são ferramentas importantes para o desempenho do trabalho educativo e do processo de atenção à saúde. Elas integram o grupo das tecnologias leves, denominadas tecnologias de relações, como acolhimento, vínculo, automação, responsabilização e gestão [3]. A utilização desses recursos tecnológicos contempla a existência de um objeto de aprendizagem, comumente definido como recurso digital com características de acessibilidade, reusabilidade e interoperabilidade [4].

O uso de TICs modernas e corretamente projetadas pode reduzir os índices de erros clínicos, melhorar o suporte dos cuidados em saúde, aumentar a eficiência de tratamentos e melhorar a qualidade de vida de pacientes. Na área da saúde, como em qualquer outra atividade, a informação deve ser entendida como um redutor de incerteza, um instrutor para detectar focos prioritários, levando a um planejamento responsável e à execução de ações que condicionem a realidade às transformações necessárias [5].

Esses dois campos tecnológicos, TES e TIC, podem ser trabalhados em conjunto no Sistema de Informação em Saúde (SIS). Trata-se de um mecanismo de coleta, processamento, análise e transmissão de informações necessárias para se planejar, organizar, operar e avaliar procedimentos de saúde e considera que a transformação de um dado em informação exige análise, divulgação e recomendações para a ação [6].

As TICs possuem vasta aplicabilidade no contexto da educação e, atualmente, vêm se tornando importantes ferramentas no auxílio do processo de ensino-aprendizagem também na área da saúde [7]. A Interactive Spaced Education (ISE), por exemplo, é uma ferramenta de e-learning que surgiu como método inovador para otimização do aprendizado em saúde nos cursos de medicina.

O desenvolvimento de TICs na área de saúde vem contribuindo também no tratamento de doenças crônicas. O Sistema Educacional para Auxiliar no Tratamento de Diabetes Mellitus Tipo 2, por exemplo, é um protótipo de um dispositivo educacional de monitoramento em saúde, desenvolvido para permitir a interação com o usuário em tratamento de diabetes mellitus tipo 2 [8].

A ampla utilização de recursos tecnológicos no aperfeiçoamento de diversas áreas da saúde e as vantagens oferecidas pelas TICs na disseminação do conhecimento aliadas às necessidades do Laboratório de Imunologia e Biologia Molecular (LIB) da Universidade Federal do Piauí culminaram no desenvolvimento de uma ferramenta de ensino-aprendizagem eletrônica, denominada EpLearning, criada para capacitar profissionais para a execução da tarefa de Análise da Reatividade Epitópica -tarefa de extrema importância para a avaliação de risco imunológico em transplantes de órgãos.

Esse artigo expõe as necessidades que levaram à criação da ferramenta EpLearning, ressaltando a relevância da utilização das TICs para solucionar a problemática inicial e os resultados finais obtidos, bem como nossos planos para extensão da ferramenta.

A organização deste artigo foi feita da seguinte forma: a seção 2 Contexto de uso e relevância da ferramenta EpLearning. A seção 3 apresenta a metodologia utilizada para o desenvolvimento da ferramenta e a seção 4 mostra os detalhes da interface com o usuário e funcionamento da ferramenta EpLearning, além dos resultados obtidos. Por fim, na seção 5, encontra-se a conclusão deste trabalho.

\section{Contexto de uso e relevância da ferramenta EpLearning}

A compatibilização entre doadores e receptores é de extrema importância para a avaliação de risco imunológico em transplantes. Anticorpos anti-HLA reconhecem áreas específicas nos antígenos HLA (Human Leukocyte Antigen), denominadas epítopos. Nos últimos vinte anos, René Duquesnoy vem descrevendo epítopos presentes na superfície das moléculas HLA através da identificação de grupos de aminoácidos polimórficos nãopróprios expostos que determinam a especificidade dos anticorpos anti-HLA [9]. A identificação dos epítopos potencialmente imunogênicos é o objeto de interesse da Análise da Reatividade Epitópica que objetiva indicar os principais epítopos responsáveis pela imunogenicidade das incompatibilidades HLA entre um par doadorreceptor. 
Uma estratégia efetiva para encontrar um par doador/receptor ideal para o transplante é aplicar algoritmos de análise epitópica. René Duquesnoy desenvolveu o algoritmo HLAMatchmaker [10] que permite a seleção de doadores com disparidades HLA através da identificação de antígenos não próprios seguros para o transplante [11]. Todavia, o HLAMatchmaker não foi capaz de universalizar o uso da reatividade epitópica porque as análises de compatibilidade doador-receptor eram difíceis e demoradas de serem feitas, pois utilizavam extensas planilhas no modelo MS-Excel. O processo de Análise da Reatividade Epitópica é complexo e difícil de ser utilizado na rotina clínica devido à grande demanda de tempo e recursos humanos qualificados para realizar essa tarefa [12].

Sendo assim, em 2008, o grupo (LIB/UFPI) desenvolveu o programa EpHLA (http://ephlaconverter.ufpi.br/) que expandiu a funcionalidade do algoritmo do HLAMatchmaker. O EpHLA facilitou a Análise da Reatividade Epitópica, pois disponibilizou uma interface gráfica e um banco de dados centralizado, onde os exames de receptores e doadores eram armazenados de forma segura e estruturada em um base de dados Access [13]. No entanto, o EpHLA não previa a realização da Prova Cruzada Virtual Epitópica (EvXM) entre um doador e múltiplos receptores ou entre um receptor e diversos doadores. A EvXM indica de maneira prática e segura a ordem de receptores ideais para determinado transplante. Esta é realizada a partir dos resultados obtidos pelas análises dos painéis de Análise da Reatividade Epitópica e o resultado da tipificação HLA do doador. Assim, basicamente, o procedimento consiste em comparar os dados de tipificação HLA do doador com os do receptor para obter o número de compatibilidades e de incompatibilidades, além da pesquisa de anticorpos específicos contra o HLA do doador. Após a comparação o sistema gera uma lista de receptores segundo a indicação para o transplante.

Para suprir essa necessidade, nos propusemos a desenvolver mais essa funcionalidade e o programa passou a ser chamado de EpViX [14] (https://epvix.com.br/). O EpViX integra todos os atores envolvidos no processo de transplante, realiza a prova virtual epitópica e faz a monitorização pós-transplante da reatividade do soro do receptor.

Apesar de todo o aparato tecnológico que tem sido desenvolvido para apoiar o processo de transplante de órgãos, a Análise da Reatividade Epitópica continua a ser uma tarefa complexa e demorada. A despeito de sua importância para o transplante, o processo de Análise da Reatividade Epitópica não dispõe de uma literatura específica, além dos recursos humanos capacitados a oferecer um treinamento específico nesta área ainda serem limitados em todo o mundo. Essa problemática tem prejudicado a disseminação e uso do EpVix. Pois para que a prova virtual epitópica - produto final do EpVix - possa ser realizada é necessário que a análise da reatividade dos painéis dos receptores em lista de espera esteja finalizada e disponível para o cruzamento.

Com o objetivo de facilitar o treinamento dos usuários do EpViX na tarefa específica da Análise da Reatividade Epitópica, propôs-se a construção de uma ferramenta auxiliar de ensino-aprendizagem a distância, denominada EpLearning (http://eplearning.pmadt.com.br), capaz de treinar os usuários inexperientes para realizarem a Análise da Reatividade Epitópica, via sistema EpVix, bem como fornecer-lhes conceitos de imunologia essenciais ao processo de análise. O EpLearning facilita o processo de uso do EpVix, pois fornece um suporte educacional consistente e sempre disponível para a capacitação de novos usuários no processo de Análise da Reatividade Epitópica.

\section{Desenvolvimento da ferramenta}

\subsection{Protocolo de estudos}

Inicialmente foi realizado um estudo aprofundado da parte teórica inerente ao tema. O conhecimento necessário para se fazer a análise da reatividade epitópica foi adquirido por meio de leitura de artigos de Imunologia e análise epitópica, e do acompanhamento e orientação de especialistas do LIB. As informações mais importantes extraídas nesta fase de desenvolvimento e que foram indispensáveis para o entendimento do problema, estão descritas a seguir:

\section{- Single Antigen}

Exame laboratorial para pesquisa de anticorpo pré-formado anti-HLA realizado de rotina para todos os casos que estão em lista de espera por um órgão de doador falecido. $\mathrm{O}$ exame consiste em identificar a 
especificidade do anticorpo anti-HLA isotipo IgG existente no soro do receptor. A técnica utilizada pelo exame é a leitura da média de fluorescência emitida (MFI) a partir da ligação do anticorpo com moléculas recombinantes HLA existentes na superfície de beads marcadas com fluorescência em comprimento de onda diferentes. Cada teste contem 100 beads.

A bead 1 não contém nenhum tipo de molécula em sua superfície e por isso é considerada como a partícula controle negativo. A bead 2 contém moléculas de imunoglobulina G humana na sua superfície e é então considerada como a partícula controle positivo no teste. As demais beads contêm moléculas HLAs específicas e únicas sendo importantes para detecção de anticorpos com a referida especificidade.Dessa forma, o teste permite determinar as especificidades de anticorpo anti-HLA existentes no soro do receptor.

- $\quad$ Self

Alelos próprios do receptor, para os quais não se espera formação de anticorpos. Com base no dogma da imunologia, que diz que não se constrói rejeição contra o próprio, os eplets relativos aos alelos próprios são excluídos de todos os demais alelos.

- Cutoff

O cutoff é obtido a partir da análise do índice médio de fluorescência (MFI) das 100 beads analisadas no teste de single antigen. $\mathrm{O}$ valor inicial do cutoff pode ser determinado de acordo com o self do paciente. Para pacientes com valor médio de self menor ou igual a 500 o valor inicial do cutoff é 500 , para pacientes com valor médio de self maior que 500 o valor inicial do cutoff é o valor do self. Definido o cutoff, a análise do painel pode ser realizada. Na análise do painel, valores iguais ou acima do valor de cutoff são considerados positivos e, valores abaixo do valor de cutoff são considerados negativos.

- Eplets

Para cada alelo no painel de reatividade são listados os eplets que compõe as porções da molécula HLA com possibilidade de imunogenicidade; Os eplets fracamente imunogênicos são os que aparecem em alelos com valor de florescência menor que o cutoff, são exibidos na cor azul. Os eplets potencialmente imunogênicos são os que aparecerem apenas em alelos positivos (valor de fluorescência maior ou igual ao valor de cutoff), são exibidos na cor amarelo.

- Alelos

Definido o cutoff, os alelos positivos são aqueles com MFI acima ou igual ao valor de cutoff e, os alelos negativos são aqueles abaixo. Os alelos serão listados como a mismatches aceitáveis se não possuírem nenhum eplet fortemente imunogênico, caso contrário os alelos serão considerados inaceitáveis.

Dando prosseguimento à pesquisa foram feitas análises de alguns painéis single antigen, disponíveis para testes, com o intuito de conhecer os procedimentos utilizados pelos analistas e identificar padrões de análise que pudessem ser implementados na ferramenta educacional. Nesta etapa houve interação constante entre pesquisadores do LIB e o responsável pelo desenvolvimento do projeto. Por fim foram selecionadas duas análises epitópicas distintas, com diferentes níveis de complexidade, para compor os casos de uso da ferramenta.

\subsection{Mapeamento do conhecimento}

Os ensinamentos propostos pela ferramenta, em forma de dicas textuais, baseiam-se em conhecimento humano, especificamente de especialistas da área de imunologia que tratam de problemas que necessitam de alto nível de perícia para sua solução. Para mapear o conhecimento humano para a ferramenta computacional utilizou-se técnicas de engenharia do conhecimento, onde um especialista humano compartilha seus conhecimentos e técnicas, utilizados para resolver de forma satisfatória as situações recorrentes da sua área de especialidade, com um analista de sistemas computacionais especialistas, que faz o mapeamento do conhecimento humano para o computador. O conhecimento em Análise da Reatividade Epitópica mapeado para os casos de uso da ferramenta está representado nas instruções a seguir.

1. O controle positivo deve ser maior que 5000 e o controle negativo menor que 500. Essa análise deve ser feita antes de iniciar a Análise da Reatividade Epitópica; 
2. Deve ser determinado um valor inicial para o cutoff : Para pacientes com valor médio de self menor ou igual a 500 o valor inicial do cutoff é 500. Pacientes com valor médio de self maior que 500, o valor inicial do cutoff é o valor médio do self. Definido o cutoff inicial, pode-se iniciar a Análise da Reatividade Epitópica;

3. Devem ser desconsiderados todos os eplets em cor azul no painel de Análise da Reatividade Epitópica;

4. Deve-se analisar todos os eplets destacados em amarelo ou vermelho, pois estes são eplets reativos e específicos, respectivamente (atentar para os valores de MFI das linhas onde estão presentes e o número de repetições no painel);

5. Após a análise dos eplets é hora de compará-los e identificar os principais causadores de reatividade seguindo os seguintes critérios de seleção:

a. Eplets mais frequentes no painel;

b. Eplets presentes em alelos que não possuem outros eplets reativos (eplets específicos);

c. Eplets que aparecem nos alelos que possuem os maiores valores de MFI;

d. Eplets que só aparecem em alelos com altos valores de MFI e que, quando ausente em um desses alelos com altos valores de MFI, há uma queda no valor do MFI maior ou igual a $30 \%$;

e. Em caso de empate, havendo mais de um possível eplet responsável pela reatividade, deve-se consultar o Epitope Registry (https://www.epregistry.com.br) para verificar se o eplet é confirmado, exposto, provisório ou indefinido, onde cada uma dessas classes possui, respectivamente, um peso de valor decrescente.

Além de analisar os eplets/epitopos causadores da reatividade, é preciso ajustar o cutoff à medida que a seleção ou descarte de eplets/epítopos é feita. A determinação do cutoff final pode seguir heurísticas diferentes, dependendo das especificidades de cada caso de Análise da Reatividade Epitópica, no entanto, para os especialistas, a melhor heurística é a que consegue justificar mais alelos reativos com a menor quantidade de eplets/epitopos selecionados.

\subsection{Protocolo de Desenvolvimento}

A ferramenta foi implementada em linguagem de programação orientado a objeto PHP, usando o ambiente de Desenvolvimento Integrado (Integrated Development Environment - IDE) PhpStorm [15]. Utilizou-se também a ferramenta Smarty, que é um sistema de templates para PHP [15]. A ferramenta Smarty permite facilmente separar a lógica da aplicação (código em PHP) do conteúdo de apresentação (código em HTML). A estilização da página foi feita por meio de CSS que é uma linguagem de folhas de estilo utilizada para definir a apresentação de documentos escritos em uma linguagem de marcação.

A linguagem de programação JavaScript, foi utilizada para controlar o HTML e o CSS e, dessa forma, manipular o comportamento da página (efeitos e animações). Usou-se também a metodologia AJAX que designa um conjunto de técnicas para programação e desenvolvimento web que utiliza tecnologias como JavaScript e XML para carregar informações de forma assíncrona. O desenvolvimento em AJAX permite a criação de páginas mais criativas e com maior interação com o usuário. A ferramenta funciona em ambiente virtual e precisa apenas de um computador com browser e internet.

\section{$4 \quad$ Interface com o usuário e funcionamento do EpLearning}

A ferramenta EpLearning é um ambiente de treinamento com a interface propositalmente semelhante a interface do sistema EpVix, sistema para o qual ela se propõe a treinar futuros usuários. A similaridade implica em consistência no treinamento, pois retrata o uso real da ferramenta em um ambiente seguro de simulação. A ferramenta apresenta ao usuário os alelos com os respectivos eplets potencialmente e fracamente imunogênicos. Para os alelos próprios do receptor espera-se que não haja formação de anticorpos e, portanto o resultado será 
negativo. Os eplets relativos a esses alelos são excluídos de todos os alelos (baseado no dogma da imunologia que diz que não se constrói resposta imune contra o próprio).

Eplets fracamente imunogênicos aparecem em alelos em que há formação de anticorpos em baixos títulos (alelos negativos). De posse desse resultado, o programa localiza estes eplets nos demais alelos, destaca-os e marca-os em azul. Eplets potencialmente imunogênicos são os eplets exclusivos dos alelos em que o receptor apresenta altos títulos de anticorpos pré-formados contra o alelo HLA. Estes eplets aparecem em amarelo.

\subsection{Vídeo de introdução}

A ferramenta dispõe de um vídeo de introdução à análise epitópica, desenvolvido utilizando a ferramenta Camtasia Studio (http://camtasia-studio.softonic.com.br/), onde são apresentadas as diferentes variáveis envolvidas no processo de análise: cutoff, controle positivo, controle negativo, alelo, eplet/epítopo, MFI, cores dos epítopos específicos, entre outras. Essas definições trazem conceitos de imunologia e análise epitópica essenciais para o entendimento dos painéis de análise.

\subsection{Níveis de análise dos casos de uso da ferramenta}

Os casos de uso possuem níveis de complexidade crescente. Para cada caso, conceitos em forma de dicas textuais pertinentes ao nível de análise em que o usuário se encontra serão introduzidos, conduzindo-o no processo correto de análise até que o resultado final satisfatório seja encontrado em cada um dos níveis percorridos.

A divisão e composição dos níveis de análise foi feita da seguinte forma:

- Para o nível 1 foi escolhido um painel de análise de grau de complexidade simples, com o objetivo de levar o usuário a aferir as definições disponibilizadas no vídeo introdutório. Nesse nível, o usuário pode analisar se os valores de Controle Positivo e Controle Negativo estão dentro dos limites aceitáveis, podendo também criar uma primeira lista de epítopos imunogênicos, que é o objetivo principal da análise.

- No nível 2 o usuário irá dispor de uma análise de grau de complexidade moderado. Nesse nível o usuário encontra muitos eplets suspeitos de serem responsáveis pelas altas taxas de MFI, o que irá dificultar as suas escolhas. Para identificar os eplets certos, o usuário precisará analisar o painel com diferentes valores de cutoff para ver quais epítopos se sobressaem em quantidade de repetição e a relevância dos locais onde aparecem, bem como outros detalhes que lhe serão apresentados no painel de dicas.

\subsection{Interface da ferramenta}

A interface criada para a ferramenta é similar a interface do EpVix e dispõe de 3 opções de menu para o usuário, como mostra a Figura 1.

$\mathrm{O}$ controle de acesso à ferramenta é feito por meio do cadastro prévio de nome de usuário e senha. $\mathrm{O}$ acesso ao sistema é liberado apenas para profissionais da área de transplantes com interesse em aprimorar seus conhecimentos em análise epitópica. No menu Imunologia, ilustrado na Figura 2, acessa-se às informações básicas necessárias para compreender uma análise epitópica.

No menu Vídeo o usuário poderá assistir ao vídeo tutorial da ferramenta de ensino-aprendizagem, como mostra a Figura 3. O mesmo também pode ser acessado no Youtube por meio do seguinte endereço: https://www.youtube.com/watch?v=cfzfBCtY2jM\&feature=youtu.be. 
Figura 1: Tela principal da ferramenta EpLearnig.

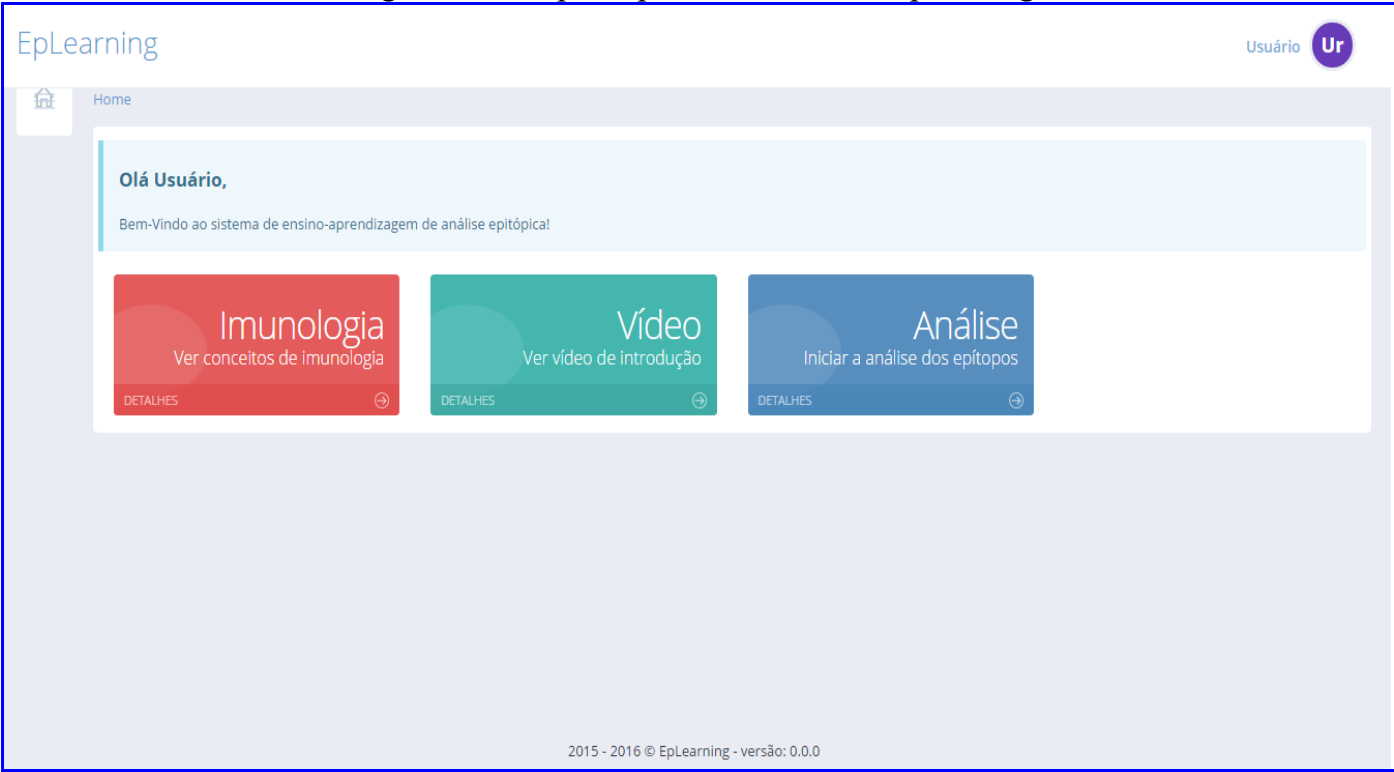

Figura 2: Tela de informações e conceitos de imunologia

\begin{tabular}{|c|c|c|}
\hline \multicolumn{3}{|c|}{ EpLearning } \\
\hline & ( A ANTÍGENO & O PONTO DE CORTE OU CUTOFF \\
\hline & 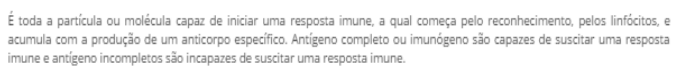 & 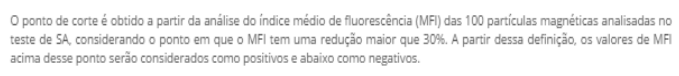 \\
\hline & \multicolumn{2}{|l|}{ O SINGLE ANTIGEN } \\
\hline & \multicolumn{2}{|c|}{ 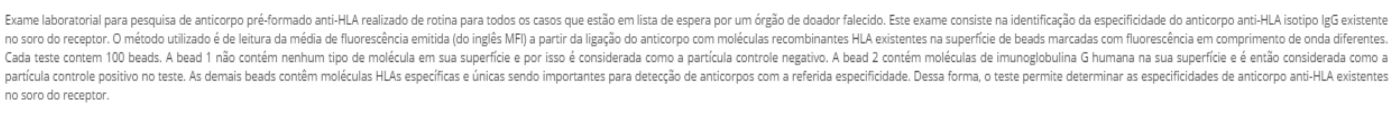 } \\
\hline & O EPLETS & O ALELOS \\
\hline & 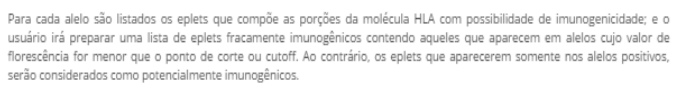 & 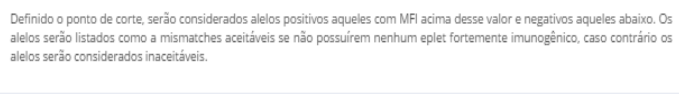 \\
\hline & \multicolumn{2}{|l|}{ O CONTROLE POSITIVO E NEGATIVO } \\
\hline & \multicolumn{2}{|c|}{ 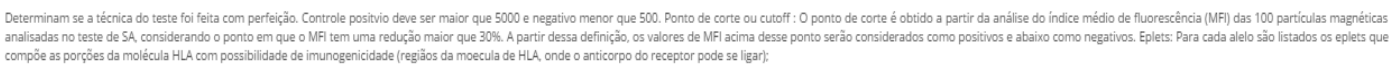 } \\
\hline & $2015-2016 \ominus$ Eplearm & rrsâa: 0.0 .0 \\
\hline
\end{tabular}


Figura 3: Tela de exibição do vídeo tutorial da ferramenta.

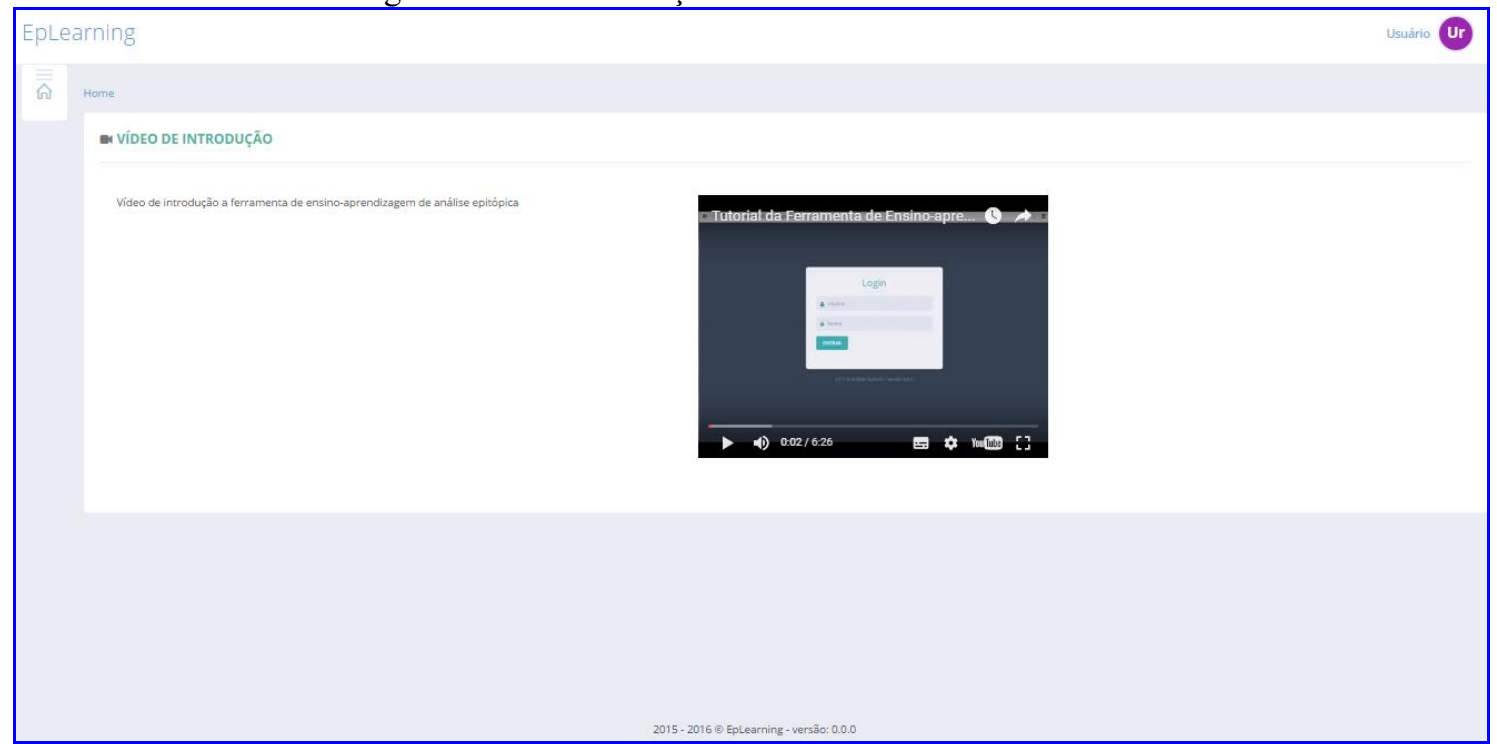

No menu Análise, o usuário tem acesso aos dois casos de análise disponíveis para aprendizagem. A Figura 4 mostra a interface do ambiente de ensino-aprendizagem disponível no referido menu.

Figura 4: Tela de ensino-aprendizagem de análise epitópica

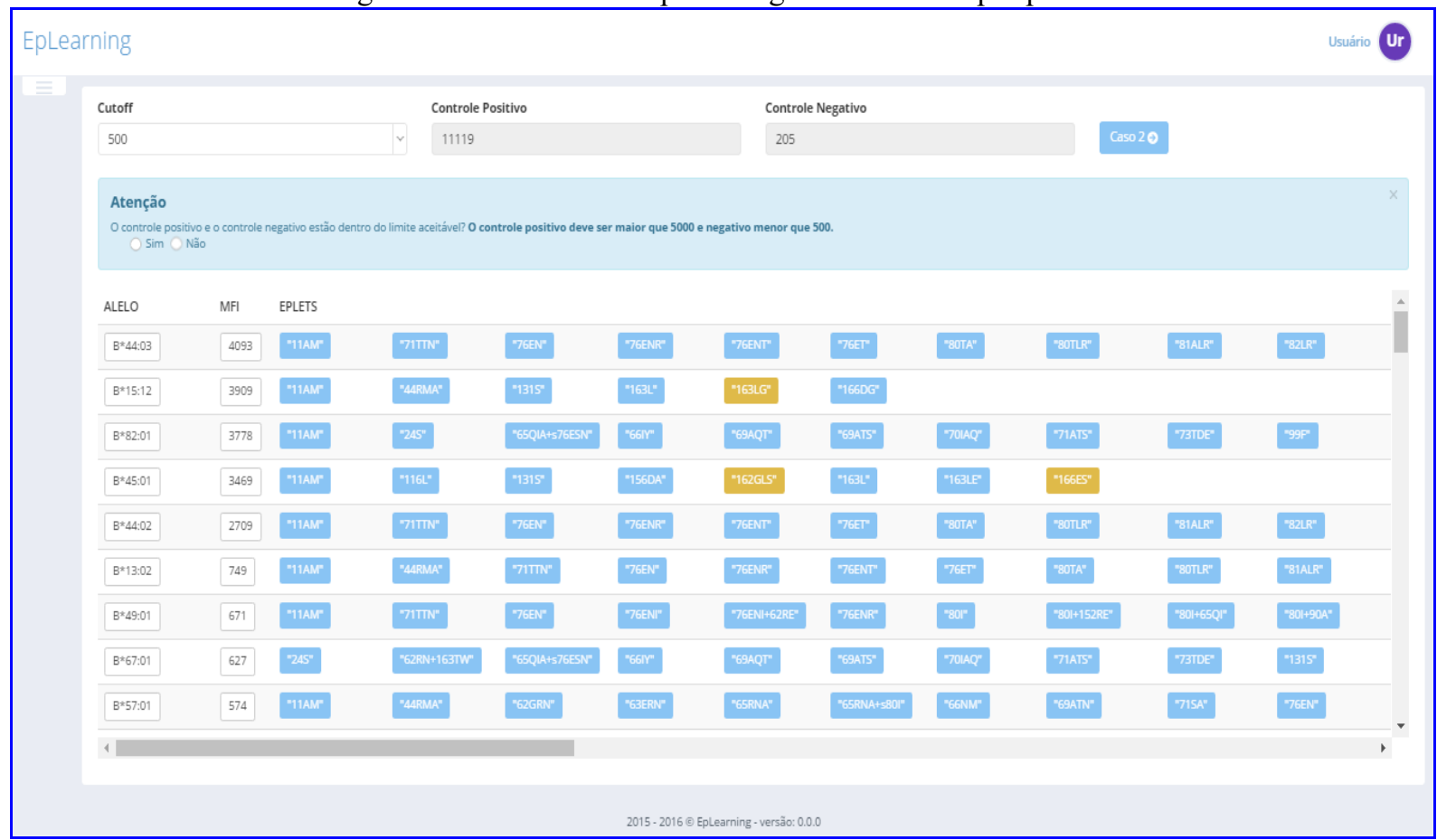


O usuário é instruído, no decorrer da sua aprendizagem, pela caixa de dicas textuais, destacada na cor azul, que fica sempre visível e o conduz no processo prático de análise do painel single antigen. Essas dicas funcionam como um tutor on-line, sugerindo o que deve ser feito pelo usuário em cada momento da sua interação. O painel de dicas é controlado pelo usuário que, ao executar o comando sugerido, deverá clicar no link "próxima dica" e prosseguir a sua análise, como mostra a Figura 5.

Figura 5: Tela de análise com ênfase na caixa de dicas textuais.

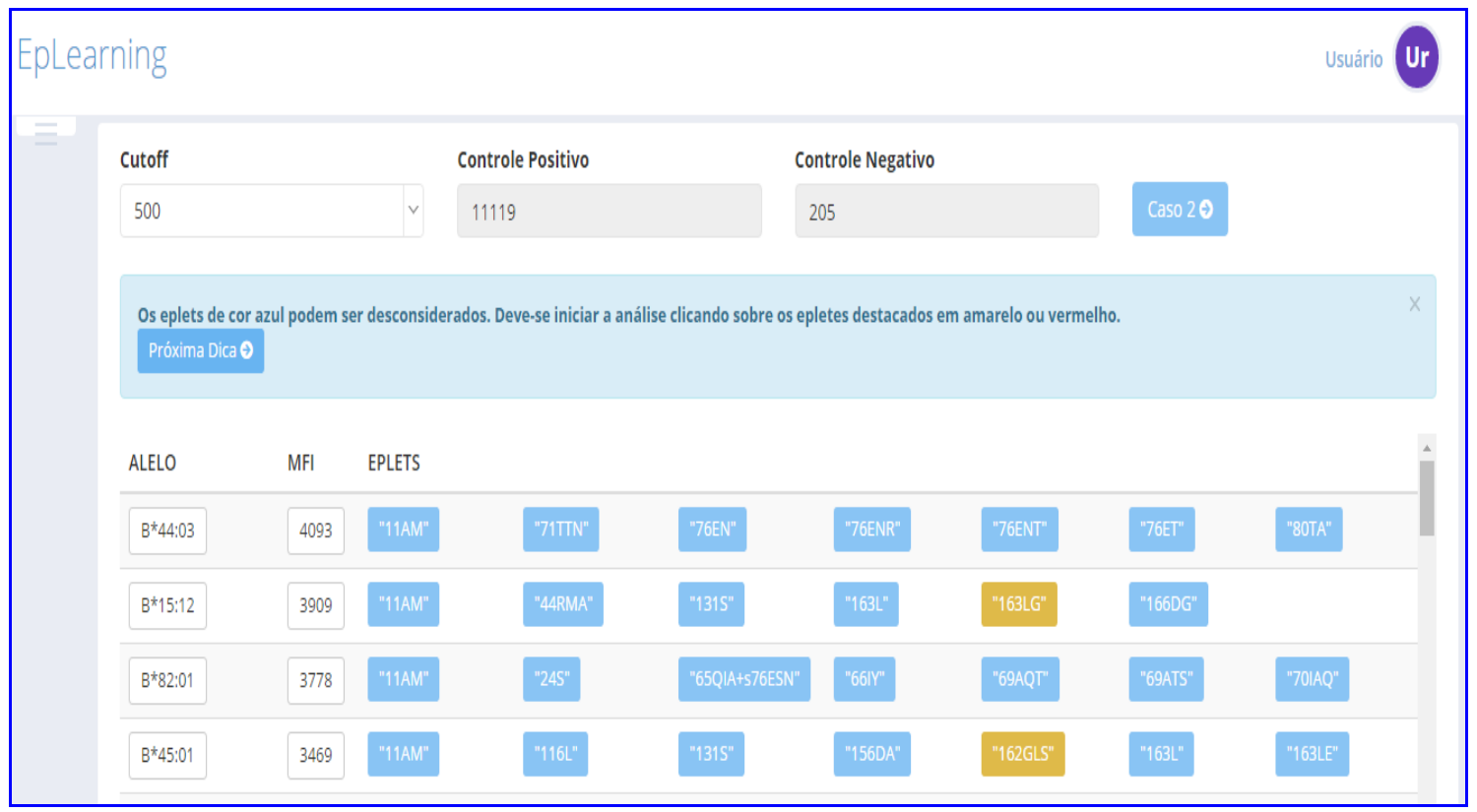

Assim, o processo de análise vai sendo instruído através da exibição dessas dicas preestabelecidas com base na análise manual feita pelo especialista no laboratório.

Para iniciar a análise, a primeira informação que o usuário precisa verificar é os valores dos controles positivo e negativo. Uma vez verificado os controles, as dicas textuais que orientam o usuário no processo de análise epitópica começam a aparecer na tela. Ao selecionar um eplet, todos os outros eplets iguais ao eplet selecionado serão destacados com a mesma cor, para que o usuário possa fazer comparações, avaliar a relevância de cada eplet na análise e ver o seu compartilhamento em todos os alelos do painel. Conforme o usuário seleciona eplets dentro do painel, novas dicas textuais vão sendo apresentadas com cores diferentes para que sejam notadas instantaneamente.

\section{Considerações finais e trabalhos futuros}

Os insumos produzidos nesta pesquisa viabilizaram a produção de uma ferramenta computacional que atendeu satisfatoriamente às necessidades dos profissionais da área de transplantes, uma vez que a ferramenta foi utilizada por pesquisadores ingressos no grupo de pesquisa e está substituiu satisfatoriamente o treinamento em análise epitópica que antes era realizado por especialista da área. A ferramenta EpLearning já possui aplicabilidade e utilidade por unir o treinamento prático e o embasamento teórico que o aprendiz necessita pra consolidar seu aprendizado. O treinamento virtual concedido por essa primeira versão da ferramenta EpLearning disponibiliza aos seus usuário a fundamentação necessária para realizar a Análise da Reatividade Epitópica. Os conceitos e técnicas adquiridos por meio das ações do aprendiz e do feedback da ferramenta são primordiais para todos os painéis de análise nos quais os aprendizes terão que analisar futuramente. No entanto, considerando que cada painel de análise possui suas particularidades e graus de dificuldades diferentes, o amadurecimento das técnicas de análise só será definitivamente absorvido pelos aprendizes com o desenvolvimento de várias atividades práticas. Por essa razão, e para honrar o compromisso de ensino no qual a ferramenta se propõe a cumprir, novos níveis de complexidade serão implementados em trabalho futuros do grupo de pesquisa, para propiciar ao usuário que já possui alguma experiência um treinamento vasto e completo em análise epitópica. 


\section{Referências}

[1] Organização das Nações Unidas para a Educação a Ciência e Cultura - UNESCO. Comunicação e informação. TIC na educação do Brasil. $<$ http://www.unesco.org/new/pt/brasilia/communication-and-information/access-to-knowledge/ict-ineducation/>. Acesso em: 17 mar. 2016.

[2] SACCOL, A.; SCHLEMMER, E.; BARBOSA, J. M-Learning e U-Learning: Novas perspectivas da aprendizagem móvel e ubíqua. São Paulo: Pearson Prentice Hall, 2011.

[3] SANTOS, Z. M. d. A.; LIMA, H. d. P. Tecnologia educativa em saúde na prevenção da hipertensão arterial em trabalhadores: análise das mudanças no estilo de vida. Texto \& contexto enfermagem. Santa Catarina, 2008, v.17, n.1, p.90-97. ISSN $0104-0707 . \quad$ Disponível el $<$ http://www.redalyc.org/articulo.oa?id=71417110>. Acesso em: 10 fev. 2016.

[4] CAVAlCANTE, M. T. L.; VASCONCELlOS, M. M. Tecnologia de informação para a educação na saúde: duas revisões e uma proposta. Ciência \& Saúde Coletiva. Rio de Janeiro maio/jun, 2007, v.12, n.3, p.611-622. ISSN 1678-4561. Disponível em <http://www.scielo.br/pdf/csc/v12n3/11.pdf>. Acesso em: 10 fev. 2016

[5] TAN, J. Medical Informatics: Concepts, Methodologies, Tools, and Applications: Concepts, Methodologies, Tools, and Applications. IGI Global. Canada, 2008, p.1-16. ISBN13: 9781605660509. Disponível em $<$ http://www.igi-global.com/book/medical-informatics-concepts-methodologies-tools/750>. Acesso em: 10 fev. 2016

[6] LESSA, F. J. D., MENDES, A. d. C. G., FARIAS, S. F., SÁ, D. A. d., DUARTE, P. O., MELO FILHO, D. A. D. Novas Metodologias para Vigilância Epidemiológica: Uso do Sistema de Informações HospitalaresSIH/SUS. Informe Epidemiológico do SUS, Brasília, 2000, v.9, p.3-19. ISSN 0104-1673. Disponível em $<$ http://scielo.iec.pa.gov.br/scielo.php?script=sci arttext\&pid=S0104$16732000000500001 \& \operatorname{lng}=\mathrm{pt \& nrm}=$ iso\&tlng=pt>. Acesso em: 10 fev. 2016.

[7] OLIVEIRA, R.J.F; SILVA, A.X.G; BRÍGIDO, A.R.D; MAFALDA, R.S; PAULA,V.T; JUNIOR,J.D. Ferramentas de e-learning para melhoria do aprendizado em medicina. Revista Brasileira de Inovação Tecnológica em Saúde, UFRN, 2013, v.3, n.3, p.55-61. ISSN 2236-1103. Disponível em $<$ http://www.periodicos.ufrn.br/reb/article/view/4484/3902>. Acesso em: 10 fev. 2016.

[8] MONTIEL.E.M.S., BALDI.A.M., KLUTHCOYSKY.A.C.G.C., JUNIOR.A.A.C., Sistema de Educação em Saúde no Tratamento do Diabetes Mellitus Tipo 2. Anais do XXVI Simpósio Brasileiro de Informática na Educação. SBIE, 2015. p.328-337. ISSN 2316-65330. Disponível em <http://www.brie.org/pub/index.php/sbie/article/view/5180/3568>. Acesso em: 10 fev. 2016.

[9] Duquesnoy RJ, Askar M. HLAMatchmaker: a molecularly based algorithm for histocompatibility determination. V. Eplet matching for HLA-DR, HLA-DQ, and HLADP.Human Immunology 2007; 68:1225 .

[10] HLAMatchmaker; 2011. Disponível em <http://www.hlamatchmaker.net/>. Acesso em: 10 fev. 2016.

[11] DUQUESNOY, R. J. Clinical usefulness of HLAMatchmaker in HLA epitope matching for organ transplantation. Current Opinion in Immunology, England, 2008, v. 28, p. 594-601.

[12] BEYOND, D., PAWAN, K. et al. Computational Approach to Systems Biology: From Fraction to Integration and Beyond. IEEE Transactions on nanobioscience, United Sates, 2004, v.3, n.3, p. 144-152.

[13] SOUSA, L. C. et al. EpHLA: na innovative and user-friendly software automating the HLAMatchmaker algorithm for antibody analysis. Transpllmmunuol [S.I.], 2011, v. 25, n.4, p. 210-6.

[14] EpViX software. Disponível em <https://epvix.com.br/>. Acesso em: 10 fev. 2016.

[15] SANDERS, W. Learnig PHP design patterns. São Paulo: Novatec Editora, 2013. p.277.

[16] DUQUESNOY, R. J. et al. 16th IHIW: a website for antibody-defined HLA epitope Registry. Int JImmuno genet, 2013, v. 40, n. 1, p. 54-9. ISSN 1744-313X Disponível em <http://www.ncbi.nlm.nih.gov/pubmed/23136897>. Acesso em: 10 fev. 2016. 
[17] DUQUESNOY, R. J. et al. First report on the antibody verification of HLA-ABCepitopes recorded in the website-based HLA Epitope Registry. Tissue Antigens, 2014 v.83, n. 6, p. 391-400. ISSN 1399-0039. Disponível em <http://www.ncbi.nlm.nih.gov/pubmed/24828056>. Acesso em: 10 fev. 2016. 